\title{
Peer Conformity Affects Smoking Behavior among Male Adolescents in a High School in Padang, Indonesia
}

\author{
Mahathir Mahathir ${ }^{1}$, Prilya Vitamaharanie ${ }^{1}$, Hermalinda Hermalinda $^{1}$ \\ ${ }^{1}$ Faculty of Nursing, Universitas Andalas, Padang, Indonesia \\ Corresponding Author: Mahathir Mahathir (mahathirmahat@nrs.unand.ac.id)
}

Received: 22 February 2020

Revised: 20 August 2020

Accepted: 21 August 2020

\begin{abstract}
Background: Peers contribute to the development of adolescents' behavior during the transition period. Adolescents often justify their behavior with peers to confirm social norms of their surroundings. The increasing number of male adolescent smokers is raising public awareness to become acquainted with the cause of the behavior. Peer conformity is expected to be one of the vital variables to circulate smoking behavior.

Purpose: This study aimed to determine the correlation between peer conformity and smoking behavior among male adolescents in a high school in Padang, Indonesia.

Methods: A descriptive-analytical research design with a cross-sectional approach was used in this study. The samples were 154 male adolescents recruited by proportional random sampling. The data were collected using the questionnaires and analyzed using the Fisher exact test.

Results: The results showed a significant correlation between peer conformity and smoking behavior among male adolescents $(p=0.000)$. Peer conformity contributed to the development of smoking behavior among adolescents in this study.

Conclusion: Peer conformity was evident to have a significant correlation with smoking behavior among male adolescents. Increasing assertiveness and life skill ability might be a necessity to adapt to negative behavior among adolescents.
\end{abstract}

Keywords: Adolescents; peer conformity; smoking behavior; peer relationship

How to Cite: Mahathir, M., Vitamaharanie, P., \& Hermalinda, H. (2020). Peer conformity affects smoking behavior among male adolescents in a high school in Padang, Indonesia. Nurse Media Journal of Nursing, 10(2), 191-199. doi:10.14710/nmjn.v10i2.28704

Permalink/DOI: https://doi.org/10.14710/nmjn.v10i2.28704

\section{BACKGROUND}

Cigarettes and smoking behavior remain to be unsolved problems of the nation among developing countries (World Health Organization, 2019). The tobacco industries are targeting developing countries as profitable resources to increase their company revenue (Word Health Organization, 2013). The exposure of rapidly growing tobacco industry and advertisement affect all populations including adolescents. The increase of protobacco exposure among adolescents is prevalent (Agaku, Adisa, Akinyamoju, \& Agboola, 2013), and affects easy access of tobacco among adolescents. The sufficient 
supply of tobacco is worsened by the availability of social supply in adolescents. A study showed the presence of social supply of tobacco among adolescents particularly coming from friends and siblings (Gendall, Hoek, Marsh, Edwards, \& Healey, 2014). Less awareness in tobacco restriction brought adolescents to trouble-free retail access (Institute of Medicine, 2015).

The world is facing a huge number of death caused by tobacco, around 8 million or half of the smokers each year (World Health Organization, 2019). The number of tobacco smokers currently affects nearly 61.4 million people in Indonesia (World Health Organization, 2018), and 19.4\% of them are adolescents (World Health Organization, 2015). In Padang, a capital city of West Sumatra Province, Indonesia, nearly $40.1 \%$ of smokers are adolescents; this number is fairly high and highlights public attention of the situation (Antara, 2019). Indonesia has certain cultures and social conditions to generate certain behavior in adolescents (Hidayati, Hatthakit, \& Isaramalai, 2012). The world is now focused on reducing tobacco globally by implementing the Framework Convention on Tobacco Control among countries to achieve the Sustainability Development Goals of 2030. Monitoring tobacco use and policy prevention are recognized as one of the programs that should have been developed by the countries to manage the increase of newly engaged smokers (World Health Organization, 2019).

Smoking behavior is notably well known to affect individuals engaged in the use of tobacco substance negatively. Adolescent smokers could also promisingly bring other adolescents into various biological, psychological, and social problems. Health effects caused by smoking may include upper lung or respiratory infection, lung immaturity development, reduced maximum lung vital capacity, and lung cancer (Park, 2011). It is not debatable that smoking behavior also increases the development of anxiety in early adulthood (Moylan et al., 2013). Smoking behavior is also interrelated to poor academic performance and socio-economic inequalities of adolescents (Robert et al., 2019). Substance abuse and addiction are also recognized as the gateway of long-term negative impacts among adolescent smokers (Letcher, Greenhalgh, \& Winstanley, 2015).

Adolescent smoking status is related to the social influence of adolescents. A previous study showed that there is a significant association between peer smoking behavior and smoking status of adolescents (Kuendig \& Jordan, 2014). Adolescents may get along with peers who actively smoke. Peer smokers will influence non-smoking adolescents in terms of their belief and intent to try smoking (Kamimura, Ahmmad, Pye, \& Gull, 2018). Adolescents show a set of behavior to adapt to social environment in accordance to achieve social equilibrium with the majority (Zhang, Deng, Yu, Zhao, \& Liu, 2016). Theories of conformity recognizes this behavior as the life skill to evaluate available options naively based on the frequency experienced within a social group, without concern the practical or inferential implications (Bernheim \& Exley, 2015). This type of development will bring out the situation in adolescent smokers at school as a risk factor for other adolescents who do not smoke. Smoking behavior has the potential to influence an adolescent's decision to smoke. Hence, it is crucial to identify the essential factors related to adolescents' smoking behavior and how peer conformity affects the smoking behavior among adolescents. 


\section{PURPOSE}

This study aimed to determine the correlation between peer conformity and smoking behavior among male adolescent smokers in a high school in Padang, Indonesia.

\section{METHODS}

\section{Design and samples}

This study used a descriptive-analytical research design with a cross-sectional approach to describe the correlation between peer conformity and smoking behavior among male adolescents. The samples were 154 male adolescent students who met the study criteria and recruited by using proportional random sampling. The inclusion criteria were adolescent students of grade VII, VIII, and IX, males, being present at the current time of the study, and smoked. The exclusion criteria were students expressing unwillingness to participate in the study, non-smoking students, and having psychological or social impairment. The number of male students from each grade was calculated, and then, the samples were determined by how many students were considered to represent their groups according to the sample distribution. In overall, the numbers of samples from grade VII, VIII, and IX were 38,66 , and 50 students, respectively.

\section{Research instrument and data collection}

This study used the peer-conformity and smoking behavior questionnaires in Indonesian language developed by Pratami (2013). The peer conformity questionnaire consists of 35 narrative questions with three dimensions: closeness, consensus, and obedience. The level of conformity is considered high if the score is $>105$, moderate if the score is between 70 105 , and low if the score is $<70$. The smoking behavior questionnaire consists of 41 narrative questions with four elements: perception of smoking benefits, smoking intensity, smoking identical place, and time of smoking. The smoking behavior is considered high if the score is $>123$, moderate if the score is between $82-123$, and low if the score is $<82$. The instruments used Likert scales with favorable and unfavorable statements. The validity and reliability of the instruments were tested. The correlation index of the peer conformity questionnaire was $0.365-0.442$ and the correlation index of the smoking behavior questionnaire was 0.372-0.467. The data were collected by distributing the questionnaires to the respondents in January 2019. The respondents completed the questionnaires within 15 to 30 minutes.

\section{Data analysis}

Univariate analysis was performed to analyze the frequency distribution of peer conformity and smoking behavior among male students. The Fisher exact test was used to determine the correlation between peer conformity and smoking behavior.

\section{Ethical considerations}

This study was strictly compiled to the ethical guidelines and considerations during the research activities. Ensuring that there was no harm to all respondents was maintained. The respondents were provided with essential research ethics such as autonomy, beneficence, non-maleficence, confidentiality, and justice. They were also informed of the purpose of the study and signed an informed consent. The study obtained ethical approval from the Research Ethics Committee of the Faculty of Medicine, Universitas Andalas with certification number of 638/KEP/FK/2018. 


\section{RESULTS}

The results of the study showed the distribution of peer conformity, smoking behavior, and the correlation between peer conformity and smoking behavior in male adolescent smokers in a high school in Padang, Indonesia. The distribution of peer conformity and smoking behavior is presented in Table 1 .

Table 1. The frequency distribution of peer conformity and smoking behavior in male adolescent students $(n=154)$

\begin{tabular}{lrrrr}
\hline \multirow{2}{*}{ Levels } & \multicolumn{2}{c}{ Peer Conformity } & \multicolumn{2}{c}{ Smoking Behavior } \\
\cline { 2 - 5 } & $f$ & $\%$ & $f$ & $\%$ \\
\hline High & 63 & 40.9 & 85 & 55.2 \\
Moderate & 80 & 51.9 & 45 & 29.2 \\
Low & 11 & 7.1 & 24 & 15.6 \\
Total & 154 & 100 & 154 & 100 \\
\hline
\end{tabular}

Table 1 showed that a majority of adolescent students (51.9\%) had a moderate level of peer conformity, and the other $40.9 \%$ with high conformity. It can also be inferred that the percentage of adolescent smoking behavior status was dominantly high (55.2\%).

The correlation between peer conformity and smoking behavior is presented in Table 2 . It can be seen that among 63 male students presenting a high level of peer conformity, there were 48 (76.2\%) students with high smoking behavior status, 11 (17.5\%) students with moderate smoking behavior status, and 4 students $(6.3 \%)$ with low smoking behavior status. Among 80 students with moderate peer conformity, 35 (43.8\%) students had high smoking behavior status, $33(41.2 \%)$ students had moderate smoking behavior status, and $12(15.0 \%)$ students had low smoking behavior status. On the other hand, $2(18.2 \%)$ students out of 11 students with a low level of peer conformity showed high smoking behavior status. The statistical analysis using the Fisher exact test showed a significant correlation between peer conformity and smoking behavior among male students with $p=0.000(p<0.05)$.

Table 2. The correlation between peer conformity and smoking behavior in male adolescent students $(n=154)$

\begin{tabular}{|c|c|c|c|c|c|c|c|c|c|}
\hline \multirow[t]{3}{*}{ Peer Conformity } & \multicolumn{6}{|c|}{ Smoking Behavior } & \multirow{2}{*}{\multicolumn{2}{|c|}{ Total }} & \multirow[t]{3}{*}{$p$-value } \\
\hline & \multicolumn{2}{|c|}{ High } & \multicolumn{2}{|c|}{ Moderate } & \multicolumn{2}{|c|}{ Low } & & & \\
\hline & $f$ & $\%$ & $f$ & $\%$ & $f$ & $\%$ & $f$ & $\%$ & \\
\hline High & 48 & 76.2 & 11 & 17.5 & 4 & 6.3 & 63 & 100 & 0.000 \\
\hline Moderate & 35 & 43.8 & 33 & 41.2 & 12 & 15.0 & 80 & 100 & \\
\hline Low & 2 & 18.2 & 1 & 9.1 & 8 & 72.7 & 11 & 100 & \\
\hline
\end{tabular}

\section{DISCUSSION}

This study investigated the correlation between peer conformity and smoking behavior among male adolescents in a high school in Padang, Indonesia. The results showed that a majority of students had high and moderate levels of peer-conformity, amounted to $40.9 \%$ and $51.9 \%$, respectively. This research highlighted the level of peer conformity among 
adolescents is in the medium category without any less considerable significant number of adolescents in the high category. Most of the moderate and high levels of peer conformity adolescents present the highest number of high smoking behavior status. Conformity in adolescents represents an adaptation of adolescents to the referent group that they follow. Adolescent males tend to have higher conformity than female adolescents (Cakirpaloglu, Lemrova, Kvintova, \& Vevodova, 2016). The adolescent needs to confirm their behavior with social norms surrounding them, in order to be accepted and recognized for their presence in the group regardless of the consequences of the behavior or an act. Adolescents with a high level of conformity tend to follow their peers with smoking behavior. Adolescents in a social group will voluntarily follow their peers and peer leaders. Theories also stated that adolescents will determine themselves by following their peer leaders and peer groups to increase their relatedness to each other (Lundberg \& Berrett, 2010).

Adolescents have crucial and robust needs to be liked by their surrounding and accepted by friends and larger peer groups. The feeling of acceptance contributes to pleasurable feelings when they experience it. On the contrary, adolescents will experience severe stress and anxiety when they are being excluded and disparaged by their group. Most of the adolescents think it is essential to be seen and to be recognized by the others (Santrock, 2014). The visibility of adolescent social groups in male adolescents also tends to create a negative climate of behavior (Schmidt, Claire, Parrott, \& Tharp, 2018). Internal cohesion between peers in the adolescent social network also forms a consensus between members of the group to specific behavior like smoking (Fisher, 2017). Males adolescents will find it hard to ignore and defend themselves not to try and deny peer pressure of smoking. Surrounded by peers who smoke will be associated with adolescent smoking trial experience and smoking continuity (Liu, Zhao, Chen, Falk, \& Albarracín, 2017).

This study also confirms that there is a significant correlation between peer conformity and smoking behavior among adolescents. There is evidence showing that peer conformity is interrelated with smoking behavior among adolescents with smoking social peer groups (Seo \& Huang, 2012). Another study also examined the relationship between peer conformity and the intention of smoking among adolescents. Smoking adolescents had less self-control to conduct and justify the situations of the social environment (Fauzan, Firman, \& Daharnis, 2018). Peer conformity is identical to the closeness of the adolescent with the members of their social peer group. The initiation of smoking in adolescents is positively correlated with peers' smoking if they have interpersonal closeness between adolescents and the member of their social peer group (Liu et al., 2017).

Peer conformity is also marked by their obedience into the member of the group. The desire of adolescents to be in the group makes adolescents try to adjust themselves by always obeying their peers' opinions and behaviors regardless of the consequences of their behavior. Obedience will gain trust from the member of the group. A study showed that peer groups would influence the decision and behavior of the following members both positively and negatively. Participants in a previous study expressed the good, scary, and powerful peer influence at once (Moguel, 2015). The consensus between adolescents makes adolescents absorbing and adjusting opinions without questioning. Adolescents 
feel responsible to respect peer opinion to create situation among group remain comfortable either non-conflicted. Smoking behavior presented by adolescents was evaluated in a study, and it was found that if adolescents having smoking friends, there was attraction for them to conduct such same behavior. Having cigarettes offered by friends push the adolescent to conduct smoking behavior. This situation gives adolescent easy access to cigarettes. Friends who provide cigarette supply and delivery are described by adolescents as easy access to cigarettes when they want to smoke because of their friend's supply (Urrutia-pereira, Oliano, Aranda, Mallol, \& Solé, 2017).

Adolescence that is identically known as life period of peers considers an important role in making decision. The influence of social circumstance during adolescence sometimes lead the adolescents to risky and maladaptive decisions. It is confirmed risky and maladaptive decisions caused by peer influence to use substances like cigarettes. Three eminent verbal models of social influence of adolescents are reward sensitivity, social motivation, and distraction (Ciranka \& Bos, 2019). Peers influence almost all life aspects of adolescents, from the more daily basic needs such as fashion, food, and sports to the more risky behavior such as smoking, use of illegal substances, or engaging in unsafe sexual practice. These bad choices may affect adolescent life-long consequences for adolescent health and put adolescents into a significant impact on their social life (Pfeifer et al., 2013).

On the other hand, friends are one of the most crucial contexts throughout adolescent positive behavior development. If it is appropriately managed and directed, it will prevent some of the personal consequences such as loneliness, well-being, health, and happiness. Friends will help adolescents to promote excellent school achievements and acquiring important social skills for adult life (Tomé, de Matos, Simões, Camacho, \& AlvesDiniz, 2012). The use of strategy to involve adolescents in preventing smoking behavior also makes an impact through developing healthy adolescent behavior. A study confirms that antismoking messages between peers affected the less intention of adolescents to try smoking (Harakeh \& van Nijnatten, 2016).

\section{CONCLUSION}

Peer conformity was evident to have a significant correlation with smoking behavior among adolescents. Assertiveness might be a necessity to adapt to negative norms of behavior among adolescents. It is pivotal to increase the life skill ability of adolescents to build such behavior in directing appropriate behavior. The future study shall compare multifactorial factors of smoking behavior among adolescents and seek modest and adaptable life skills that should be nurtured to adolescents.

\section{ACKNOWLEDGMENT}

We extend our gratitude to the Faculty of Nursing Universitas Andalas for technical and related support in this study.

\section{CONFLICT OF INTEREST}

None 


\section{REFERENCES}

Agaku, I. T., Adisa, A. O., Akinyamoju, A. O., \& Agboola, S. O. (2013). A cross-country comparison of the prevalence of exposure to tobacco advertisements among adolescents aged 13-15 years in 20 low and middle income countries. Tobacco Induced Diseases, 11(11), 1-10. doi:10.1186/1617-9625-11-11

Antara. (2019). Penelitian: perokok di Sumbar didominasi usia pelajar - ANTARA News [Research: Smokers in West Sumatra are dominated by school aged adolescents]. Retrieved from https://www.antaranews.com/berita/789367/penelitian-perokok-disumbar-didominasi-usia-pelajar

Bernheim, B. D., \& Exley, C. L. (2015). Understanding conformity: An experimental investigation. Retrieved from https://www.hbs.edu/faculty/PublicationFiles/16070_1d8d5b51-93dd-4906-b811-4436813d55db.pdf

Cakirpaloglu, S. D., Lemrova, S., Kvintova, J., \& Vevodova, S. (2016). Conformity, peer presure, popularity and risk behavior among adolescents. $9^{\text {th }}$ Annual International Conference of Education Research and Innovation Proceeding. 4078-4086. Seville, Spain: JATED.

Ciranka, S., \& Bos, W. (2019). Social influence in adolescent decision-making: A formal framework. Front Psychol, 10, 1915. doi:10.3389/fpsyg.2019.01915

Fauzan, F., Firman, F., Daharnis, D. (2018). Relationship between self-control and peer conformity with smoking behavior. Proceeding of International Conferences on Educational, Social Sciences and Technology. 233-239. Padang: Fakultas Ilmu Pendidikan UNP.

Fisher, J. C. (2017). Exit, cohesion and consensus: Social psychological moderators of consensus among adolesent peer groups. Social Current, 5(1), 49-66. doi:10.1177/2329496517704859

Gendall, P., Hoek, J., Marsh, L., Edwards, R., \& Healey, B. (2014). Youth tobacco access: Trends and policy implications. BMJ Open, 4(4), 1-8. doi:10.1136/bmjopen-2013004631

Harakeh, Z., \& van Nijnatten, C. H. C. J. (2016). Young people smokers' reactions on peer influence not to smoke. Substance Use \& Misuse, 51(13), 1693-1700. doi:10.1080/10826084.2016.1191517

Hidayati, H., Hatthakit, U., \& Isaramalai, S. A. (2012). Correlates of physical activity in Asian adolescents: A literature review. Nurse Media Journal of Nursing, 2(2), 451466. doi:10.14710/nmjn.v2i2.3976

Institute of Medicine. (2015). Public health implications of raising the minimum age of legal access to tobacco products. Washington, DC: The National Academies Press. doi:10.17226/18997.

Kamimura, A., Ahmmad, Z., Pye, M., \& Gull, B. (2018). Peer smoking and smokingrelated beliefs among college students in Bangladesh. Journal of Preventive Medicine and Public Health, 51(1), 51-58. doi:10.3961/jpmph.17.146

Kuendig, H., \& Jordan, M. D. (2014). Adolescents smoking in the crosslight of other substance use and parental and peers' smoking behaviors. ISRN Addiction, 719681. doi:10.1155/2014/719681.

Letcher, T, Greenhalgh, E. M., \& Winstanley, M. H. (2015). 3.21 Health effects for younger smokers. In Scollo, M. M, \& Winstanley, M. H (eds.). Tobacco in Australia: Facts and issues. Melbourne: Cancer Council Victoria. 
Liu, J., Zhao, S., Chen, X., Falk, E., \& Albarracín, D. (2017). The influence of peer behavior as a function of social and cultural closeness: A meta-analysis of normative influence on adolescent smoking initiation and continuation. Psychological Bulletin, 143(10), 1082-1115. doi:10.1037/bul0000113

Lundberg, N., \& Berrett, K. (2010). Adolescent peer followership: A self-determination theory perspective. Journal of Park and Recreation Administration, 28(2), 20-35

Moguel, K. (2015). The experience of influence among youth leaders (Graduate thesis). University of Nebraska.

Moylan, S., Gustavson, K., Karevold, E., Øverland, S., Jacka, F. N., Pasco, J. A., ... \& Berk, M. (2013). The impact of smoking in adolescence on early adult anxiety symptoms and the relationship between infant vulnerability factors for anxiety and aarly adult anxiety symptoms: The TOPP study. PLoS One 8(5), e63252. doi:10.1371/journal.pone.0063252

Park, S. (2011). Smoking and adolescent health. Korean Journal of Pediatrics, 54(10), 401-404. doi:10.3345/kjp.2011.54.10.401

Pfeifer, J. H., Masten, C. L., Moore, W. E., Oswald, T. M., Mazziota, J.C., Iacoboni, M., \& Dapretto, M. (2013). Entering adolescence: Resistance to peer influence, risky behavior, and neural changes in emotion reactivity. Neuron, 69(5), 1-18. doi:10.1016/j.neuron.2011.02.019.

Pratami, O. R. (2013). Hubungan antara konformitas teman sebaya dan asertivitas dengan perilaku merokok pada siswa di SMP 5 Purbalingga [The relationship between peer conformity and smoking behavior asertivity of Junior High School 5 Purbalingga] (Undegraduate Thesis). Universitas Negeri Yogyakarta, Yogyakarta.

Robert, P., Kuipers, M. A. G., Rathmann, K., Moor, I., Kinnunen, J. M., Rimpelä, ... \& Anton, E. (2019). Academic performance and adolescent smoking in 6 European cities: The role of friendship ties. International Journal of Adolescence and Youth, 3843, 1-11. doi:10.1080/02673843.2018.1475288

Santrock, J. W. (2014). Adolesence (15th ed.). New York: Mc Graw Hill Education.

Schmidt, M. R., Claire G, L., Parrott, D. J., \& Tharp, A. T. (2018). Moderating effect of negative peer group climate on the relation between men's locus of control and aggression toward intimate partners. Journal of Interpersonal Violence, 31(5), 755773. doi:10.1177/0886260514556761

Seo, D.-C., \& Huang, Y. (2012). Systematic review of social network analysis in adolescent cigarette smoking behavior. Journal of School Health, 82(1), 21-27. doi:10.1111/j.1746-1561.2011.00663.x

Tomé, G., de Matos, M. G., Simões, C., Camacho, I., \& AlvesDiniz, J. (2012). How can peer group influence the behavior of adolescents: Explanatory model. Global Journal of Health Science, 4(2), 26-35. doi:10.5539/gjhs.v4n2p26

Urrutia-pereira, M., Oliano, V. J., Aranda, C. S., Mallol, J., \& Solé, D. (2017). Prevalence and factors associated with smoking among adolescents. Jornal de Pediatria, 93(3), 230-237. doi:10.1016/j.jped.2016.07.003

World Health Organization. (2013). WHO report on the global tobacco epidemic, 2013. Enforcing bans on tobacco advertising, promotion and sponsors. Retrieved from https://apps.who.int/iris/bitstream/handle/10665/85380/9789241505871_eng.pdf;js essio

World Health Organization. (2015). WHO global report on trends in prevalence of tobacco smoking 2015. Geneva: WHO. 
World Health Organization. (2018). Factsheet 2018 Indonesia. Framework convention on tobacco control. Retrieved from https://apps.who.int/iris/bitstream/handle/10665/272673/wntd_2018_indonesia_fs. pdf? sequence $=1$.

World Health Organization. (2019). WHO report on the global tobacco epidemic 2019. Offer help to quit tobacco use. Retrieved from https://apps.who.int/iris/bitstream/handle/10665/326043/9789241516204eng.pdf?ua $=1$

Zhang, P., Deng, Y., Yu, X., Zhao, X., \& Liu, X. (2016). Social anxiety, stress type, and conformity among adolescents. Frontiers in Psychology, 7, Article 760. doi:10.3389/fpsyg.2016.00760 